\title{
Induction of B-cell lymphoma by UVB Radiation in p53 Haploinsufficient Mice
}

Nahum Puebla-Osorio ${ }^{1}$, Yasuko Miyahara ${ }^{3}$, Sreevidya Coimbatore ${ }^{1}$, Alberto Y Limón-Flores ${ }^{4}$, Nasser Kazimi ${ }^{1}$, Stephen E Ullrich ${ }^{1,2}$, Chengming Zhu ${ }^{1,2^{*}}$

\begin{abstract}
Background: The incidence of non-Hodgkin's lymphoma has increased over recent years. The exact etiology of lymphoma remains unknown. Ultraviolet light exposure has been associated with the development of internal lymphoid malignancies and some reports suggest that it may play a role in the development of lymphoma in humans. Here we describe the characterization and progression of lymphoma in p53 heterozygous mice exposed to UVB irradiation.
\end{abstract}

Methods: UVB-irradiated $\mathrm{p} 53^{+/}$mice developed enlargement of the spleen. Isolated spleen cells were transplanted into Rag deficient hosts. The UV-induced tumor cells were analyzed by flow cytometry. The tumor cells were tagged with GFP to study their metastatic potential. SKY and karyotypic analysis were carried out for the detection of chromosomal abnormalities. Functional assays included in vitro class switch recombination assay, immunoglobulin rearrangement assay, as well as cytokine profiling.

Results: UVB-exposed mice showed enlargement of the spleen and lymph nodes. Cells transplanted into Rag deficient mice developed aggressive tumors that infiltrated the lymph nodes, the spleen and the bone marrow. The tumor cells did not grow in immune competent syngeneic C57BI/6 mice yet showed a modest growth in UV-irradiated B6 mice. Phenotypic analysis of these tumor cells revealed these cells are positive for B cell markers $\mathrm{CD}_{19}{ }^{+}, \mathrm{CD}^{+}, \mathrm{B}_{22} \mathrm{O}^{+}, \operatorname{lgM}^{+}$and negative for T cell, NK or dendritic cell markers. The UV-induced tumor cells underwent robust in vitro immunoglobulin class switch recombination in response to lipopolysaccharide. Cytogenetic analysis revealed a $\mathrm{t}(14 ; 19)$ translocation and trisomy of chromosome 6 . These tumor cells secret IL-10, which can promote tumor growth and cause systemic immunosuppression.

Conclusion: UV-irradiated $\mathrm{p} 53^{+-}$mice developed lymphoid tumors that corresponded to a mature B cell lymphoma. Our results suggest that an indirect mechanism is involved in the development of internal tumors after chronic exposure to UV light. The induction of B cell lymphoma in UV-irradiated p53 heterozygous mice may provide a useful model for lymphoma development in humans.

\section{Background}

The incidence of non-Hodgkin's lymphoma has increased over recent years, an increase that cannot be totally explained by improvements in diagnosis or reporting. The exact etiology of lymphoma remains unknown but viral infection, chronic antigen stimulation, and/or immunosuppression, either primary or acquired immunodeficiency, may all contribute to the

\footnotetext{
* Correspondence: czhu@mdanderson.org

'Department of Immunology and the Center for Cancer Immunology Research, The University of Texas M.D. Anderson Cancer Center, Houston, Texas, 77030, USA

Full list of author information is available at the end of the article
}

occurrence of lymphoma [1]. Some reports suggest that exposure to the UV radiation in sunlight may play a role in the development of lymphoma in humans [2]. This conclusion is based primarily on epidemiological data showing a geographic correlation between sunlight exposure and lymphoma incidence (i.e., a latitude gradient) [3-7]. However, not all the reports supported a link between sunlight exposure and lymphoma development [8-11], some findings indicate an inverse association between the solar UVB exposure and the occurrence of non-Hodgkin lymphoma [12-15]. The rise in lymphoma incidence parallels the dramatic rise in melanoma incidence, and patients with non-Hodgkin's lymphoma or

\section{Biomed Central}


chronic lymphocytic leukemia are at a higher risk of developing skin cancer [16,17].

Studies with experimental animals suggest a strong correlation between UV exposure and lymphoma development $[18,19]$. Animal experiments offer the distinct advantage of controlled irradiation with defined UV light sources, without the complications that arise from exposure to any other environmental carcinogens or toxins, nor the complication of recall bias. We previously reported that UV irradiation augments lymphoid malignancies in mice with one functional copy of wildtype p53. In that study we demonstrated that UV irradiated p53 heterozygous mice developed lymphoid tumors at a much higher rate $(88 \%$ of irradiated mice developed tumors) than found in un-irradiated animals (6\% spontaneous tumor rate). Sequencing data indicated that the UV-irradiated $\mathrm{p}^{5} 3^{+/-}$mice retained the nonmutated p53 allele, suggesting loss of heterozygosity did not play a role in the induction of this tumor [19].

The biological effects of UV exposure are well known. UVB, wavelengths in the $280-320 \mathrm{~nm}$ range of the solar spectrum, can induce a wide variety of adverse effects. Chief among them are sunburn, inflammation, premature ageing of the skin, the induction of non-melanoma skin cancer and the induction of immune suppression (reviewed in [20]). UVA (320-400 nm) has been suggested to be important in melanoma induction [21]. It is clear that the adverse effects of UV exposure are not solely limited to the skin; how UV exposure influences lymphoma development in humans, however, is still far from being completely understood. Here we analyzed the UV-induced lymphoid malignancies that arise in mice with one functional copy of p53. We have previously analyzed UV-induced lymphoid malignancies by histopathological examination of formalin-fixed tissues. To be able to study the biology of the tumors we needed to generate tumor cell lines from UV-irradiated $p 53^{+/-}$mice. We exposed $p 53^{+/-}$mice to solar simulated UV radiation for a period of 30 weeks and then injected spleen cells into immune deficient Rag $2^{-1-}$ mice. We generated a number of transplantable tumor cells lines, some of which were further adapted to grow in vitro. We found that UV-irradiation of $p 53^{+/-}$mice resulted in the induction of B-cell tumors $\left(\mathrm{CD}^{+}, \mathrm{CD}_{1} 9^{+}, \mathrm{B}^{2} 20^{+}, \mathrm{IgM}^{+}\right)$that grew progressively in immune deficient mice, but not in immune competent animals, and grew at low rate in UV-irradiated $\mathrm{C} 57 \mathrm{Bl} / 6$ mice. We suggest the induction of $\mathrm{B}$ cell lymphomas by UV radiation in $p 53^{+/-}$mice may serve as a useful animal model for lymphoma development.

\section{Methods}

\section{Mice}

Specific pathogen-free $p 53$ knockout mice were backcrossed onto a C57Bl/6 background [19]. Specific pathogen-free Rag $2^{-1-}$ mice were obtained from Dr. Fred Alt (Howard Hughes Medical Institute, Children's Hospital, Boston, MA). All mice were housed in a pathogen-free barrier facility. The Institutional Animal Care and Use Committee approved all procedures.

\section{UV irradiation}

A 1000 W Xenon UV solar simulator equipped with a Schott WG-320 atmospheric attenuation filter and a visible/infrared band-pass filter (Oriel, Stratford, CT) was used to irradiate the mice. The intensity and spectral output was measured using an Optronics Model OL-754 scanning spectrophotometer (Optronics Lab, Orlando, FL) [22]. Seventeen p53 heterozygous mice were divided in two groups of 8 and 9 mice each for UV irradiation. The mice were shaved on the dorsal skin and were kept individually in a Plexiglas container; then, they were irradiated three times a week during 10-15 minutes for a period of 30 weeks. During this procedure the mice remained conscious all the time.

\section{Transplantation}

Cells $\left(2.5 \times 10^{6}\right)$ from enlarged spleens of the irradiated mice were injected subcutaneously into each flank of a $\operatorname{Rag} 2^{-1-}$, wild type and/or UV irradiated $\left(10 \mathrm{~kJ} / \mathrm{m}^{2}, 3\right.$ times per week for 12 weeks) $\mathrm{C} 57 \mathrm{Bl} / 6$ mouse. Mice were monitored daily for tumor development. The tumors were excised and analyzed by flow cytometry and histopathology.

\section{Flow cytometric analysis}

Cell surface molecule expression was analyzed by flow cytometry using a BD FACS-Calibur (BD Biosciences, San Jose, CA). Fluorescently-labeled monoclonal antibodies to mouse CD1d, CD3, CD4, CD5, CD8a, CD11b, CD16/32, CD19, CD23, CD25, CD38, CD40, CD43, CD44, CD45R/ B220, CD49b, CD62L, CD80, CD86, CD90, CD117, CD123, CD127, CD138, IgM and IgD, GR-1 were purchased from commercial sources (Becton-Dickinson, Mountain View, California, and eBioscience, San Diego, California).

\section{In vitro class switch recombination assay}

The cells were stimulated with lipopolysaccharide (LPS) (Sigma, St. Louis, MO), IL-4 (10ng/ml) plus CD40L (10 $\mathrm{ng} / \mathrm{mL}$ ), and a combination of CD40L/TGF $\beta$ (10 ng/mL each, all from PeproTech Rocky Hill, NJ). The cells were analyzed 96 hours later by flow cytometry using a BD FACS-Calibur or BD LSR II (Becton-Dickinson, Mountain View, California).

\section{Southern blotting analysis}

High molecular weight DNA samples were prepared from the tumor, digested with EcoR1 and hybridized 
with a $\mathrm{J}_{\mathrm{H}}$ probe using Gene images AlkPhos Direct Labeling and detection System (Amersham Biosciences, Buckinghamshire, UK).

\section{Cytogenetic analysis}

Tumor cells were cultured in the presence of Colcemid. Metaphases were analyzed with trypsin-Giemsa stain and with whole chromosome painting probes (Carlsbad, CA, USA). To analyze potential chromosomal translocations, the metaphases were also used for spectral karyotyping analysis (SKY; Applied Spectral Imaging, Inc. Vista, CA).

\section{Cell culture and lentiviral vector transduction}

Tumor cells $\left(1 \times 10^{5}\right)$ were incubated with lentiviral vectors. The number of green fluorescent protein (GFP) positive cells was analyzed by flow cytometry at multiple time points after transduction. Highly expressing GFP bearing cells were isolated by cell sorting (BD FACSAria, BD Biosciences, San Jose, CA).

\section{Cytokine determination}

Cytokine secretion of the tumor cells into the supernatant fluid was measured by the multiplexed mouse cytokine Ten-Plex Antibody Bead system (BIOSOURCE, Camarillo, CA) and the Luminex 100 fluorescence detection system (Austin, TX). Cytokines analyzed by this system include: IL-1beta, IL-2, IL-4, IL-5, IL-6, IL10, IL-12, GM-CSF, Interferon-gamma and TNF-alpha.

\section{Results \\ UV exposure induced non-skin tumors in p53 heterozygous mice}

To obtain a maximal probability of tumor development [19], we exposed $17 \mathrm{p} 53$ heterozygous mice to $10 \mathrm{~kJ} / \mathrm{m}^{2}$ of UVB radiation, 3 times a week, during 30 weeks. At the end of this period, the animals were sacrificed. Analysis of necropsy showed severe skin irritation at the irradiated area and 15 out of 17 irradiated mice developed splenomegaly and half of which also developed enlarged mesenteric lymph nodes. To assess their tumorigenic potential, cell suspensions (approximately $2.6 \times 10^{6}$ ) were prepared from the enlarged spleens and lymph nodes, and were injected subcutaneously into an immune deficient $\operatorname{Rag} 2^{-1-}$ mouse. When tumors were evident they were excised and used for cell culture and histology (data not shown). A cell suspension sample from a tumor was re-injected into 3-4 $\operatorname{Rag} 2^{-1-}$ mice. While the cells transplanted into the $\mathrm{Rag}^{-/-}$mice showed progressive growth, these cells were unable to grow ex vivo after the first in vivo passage. However, we were able to establish a cell line capable of growing in vitro after two to three additional passages through Rag2 $2^{-1-}$ mice. At each successive passage through Rag2 ${ }^{-1-}$ mice the latency period decreased, and after three passages subcutaneous tumors were noticeable at one-week post injection. This procedure was carried out several times and in all cases tumors were consistently generated in Rag2 ${ }^{-1-}$ mice. However, only cells originated from the enlarged spleens were able to grow progressively in vivo and in vitro, whereas cells originated from the enlarged mesenteric lymph nodes were not able to survive in vitro. We were able to originate three cell lines that were able to grow in vivo and in vitro.

\section{UV-exposed mice developed a matured B-cell tumor}

Phenotypic analysis was carried out using flow cytometry on the tumor cells that grew in Rag $2^{-1-}$ mice. All the cells were included in this analysis, and we avoided selecting the cells by size. These tumor cells were positive to the surface markers CD19, B220, CD5 and IgM, and also expressed the co-stimulatory molecules CD80, CD86 as well as CD117 (Figure 1A). The cells were negative for the $\mathrm{T}$ cell specific markers CD3, CD4, CD8 and Th1.2; and were negative for the markers normally found on NK cells (NK1.1, CD49b) or dendritic cells/ macrophages (CD11b). Moreover, the cells were also negative to surface markers expressed on immature $B$ cells (CD43, BP-1, CD127). Southern blotting analysis showed a rearrangement of the immunoglobulin heavy chain in the DNA of the tumor cells as compared to the non-lymphoid DNA obtained from a Rag mouse, further supporting the conclusion that the tumor cells are indeed B-cells (Figure 1B). Using G-banding on metaphase spreads from the tumor cells we found a chromosomal translocation on chr14, and a small acrocentric chromosome. Spectral karyotyping (SKY) analysis confirmed the translocation was between the chromosomes 14 and 19 in all three cell lines studied (Figure 2 shows the representative results of one cell line). The translocated region was located proximal to the telomere on chromosome 19. SKY analysis also showed a trisomy on chromosome 19 (data not shown), with a likely complete translocation to chromosome 14. SKY analysis also showed a trisomy on chromosome 6 (Figure 2). The recurrent chromosomal translocation in all three cell lines strongly implies a role in tumorigenesis. However, the molecular details regarding the potential genes involved remain to be determined.

\section{The UV transformed B cells are stable and undergo robust class switch recombination (CSR)}

To further explore whether the properties of these tumor B cells are typical of the B cell lineage, we examined their ability to undergo CSR in response to various stimuli [23]. The transformed B cells were kept in culture for 3-5 days and analyzed for spontaneous CSR. The cells with low spontaneous switching to IgG1, IgG3 


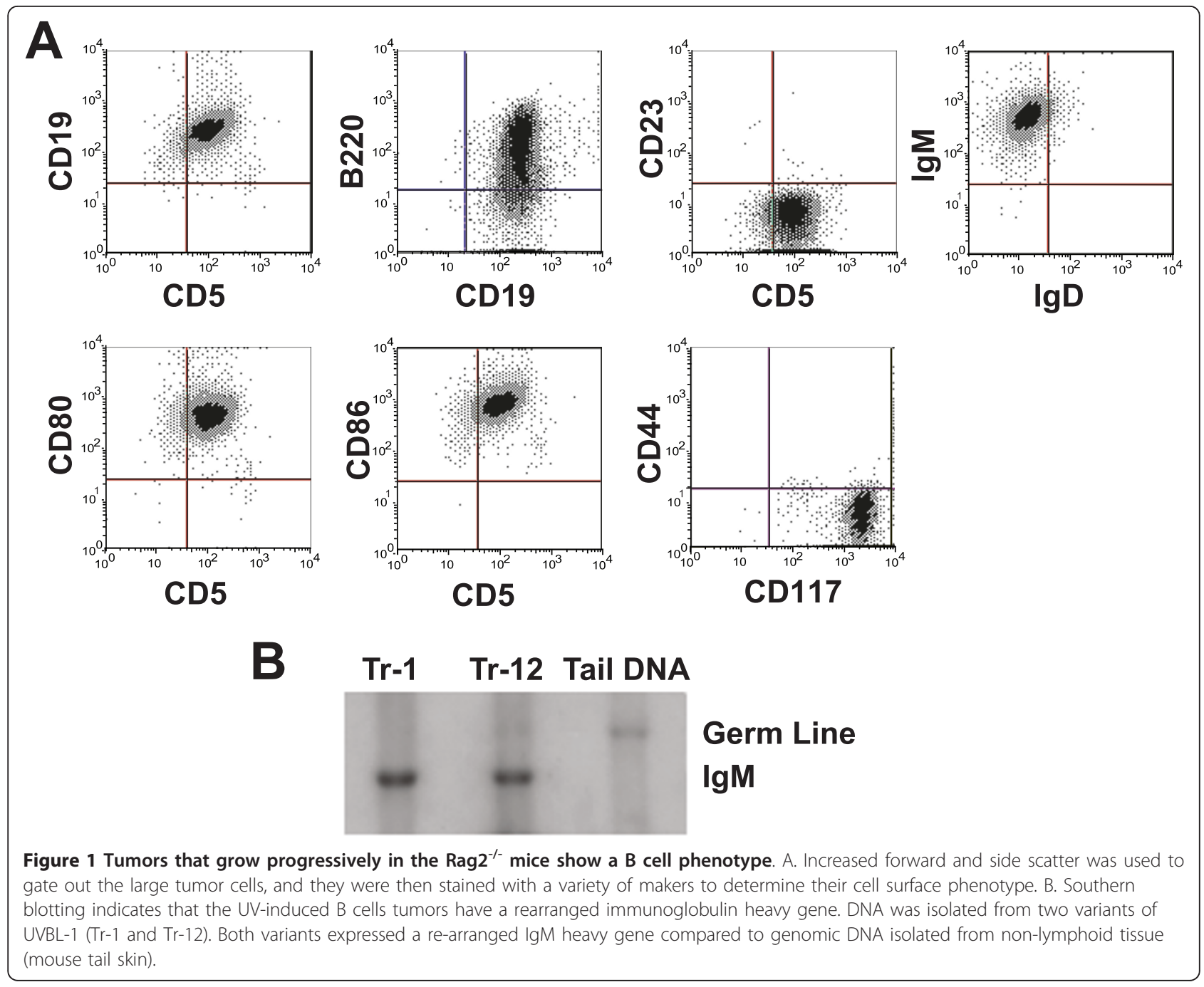

and IgG2b (Figure 3) were sub-cloned by limiting dilution; the sub-cloned cells were stimulated with 25,50 and $100 \mathrm{ng} / \mathrm{mL}$ of LPS. These experiments were performed at least six times. As shown in Figure 3A, LPS induced a robust CSR in these cells in a dose-dependent fashion from IgM to IgG2b at frequencies up to $53 \%$. However, modest CSR levels were observed after these transformed B cells were stimulated with IL-4 and CD40L or CD40L and TGF $\beta$, with frequencies of $19 \%$ to IgG1 and $29 \%$ to IgA, respectively (Figure 3B). The robustness of class switch recombination confirms the mature B cell phenotype of the transformed B cells, and the spontaneous CSR may be the result of a deregulated CSR enzymatic mechanism in this tumor cells [24].

\section{The UV-induced tumor B cells are immunogenic}

One of the hallmarks of UV-induced skin tumors is the fact that they are highly antigenic since they are recognized and destroyed by a normal immune system, therefore these cells only grow progressively in immunedeficient mice [25]. In addition, UV-induced tumors will grow in mice exposed to a subcarcinogenic dose of UV radiation. This is due to the fact that UV exposure activates the induction of $\mathrm{T}$ regulatory cells that control the growth of UV-induced tumors in the UV-irradiated host $[26,27]$. To determine the growth patterns of the UVinduced B cell tumor and determine its antigenicity, the transformed B cells were injected into three groups of mice, normal immune-competent $\mathrm{C} 57 \mathrm{BL} / 6$ mice, C57BL/6 mice exposed to a chronic course of UV radiation $\left(10 \mathrm{~kJ} / \mathrm{m}^{2}, 3\right.$ times a week for 12 weeks), and immune-deficient Rag2 ${ }^{-1-}$ mice (Table 1). Progressive tumor growth was only noted when the lymphoma cells were injected into the $\mathrm{Rag}^{-1-}$ recipients $(100 \%$ tumor incidence), significantly lower tumor incidence occurred when the cells were transplanted into wild-type mice (7\%, $\mathrm{p}<0.0001$ vs. Rag2 ${ }^{-/-}$control, Fisher exact test). Lower but not significant tumor growth was noted in 


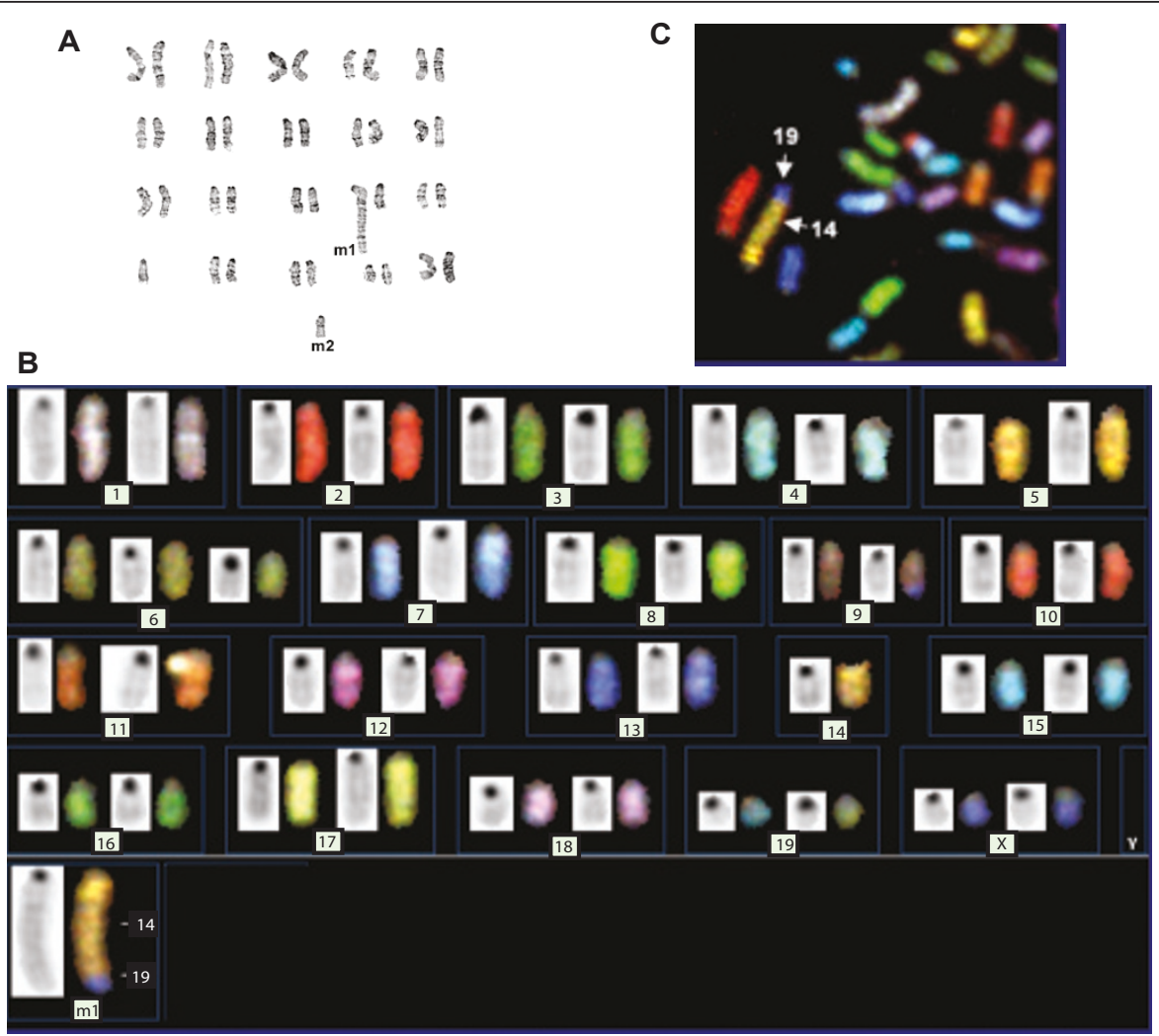

Figure 2 Analysis of chromosomal abnormalities in the UV-induced B cell lymphoma. A. G banding of metaphase spreads was prepared and indicated two abnormalities, an increase in size of chromosome 14, suggesting a translocation, and a small acrocentric chromosome (M2). B and C: Multi-color FISH confirms a translocation between chromosomes 14 and 19 and trisomal chromosome 6.

the wild type mice exposed to UV radiation after the injection of the lymphoma cells $(13 \%, \mathrm{p}<0.0001$ vs. $\operatorname{Rag} 2^{-1-}$ control, Fisher exact test). These data indicate that like UV-induced skin tumors the UV-induced tumor B cells are antigenic, but unlike UV-induced skin tumors, these cells are not recognized by UV-induced $\mathrm{T}$ regulatory cells.

The UVB induced p53 heterozygous B lymphoma cells are metastatic

UV-transformed B cells that resulted from exposing p53 heterozygous mice to UVB light were transfected with a vector expressing green fluorescent protein (GFP). The cells were sorted for both CD19 and GFP. Approximately $1 \times 10^{7}$ CD19/GFP double positive tumors cells were injected subcutaneously into $10 \mathrm{Rag} 2^{-/-}$mice. Tumor development was assessed in these animals and the tumor bearing Rag2 ${ }^{-1}$ mice were sacrificed at various time points after the injection. Flow cytometry was utilized to determine the numbers of GFP/CD19 double positive cells in various lymphoid tissues (Figure 4). Cells from the spleen and bone marrow of normal Rag $2^{-1-}$ mice were used as control. $\mathrm{CD} 19^{+}$cells were absent in all lymphoid tissues of the non-injected Rag $2^{-1-}$ mice (Figure 4A, D,
G). The $\mathrm{CD} 19^{+}, \mathrm{GFP}^{+}$cells were only found in the subcutaneous tumor 4 days post injection. On day 11 these cells were found in the draining lymph nodes (Figure 4B $\& 4 C$ ), but were absent in the spleen or bone marrow. Two populations of $\mathrm{CD} 19^{+}$cells were found in the lymph nodes (Figure 4C), one was negative for GFP (45.3\%), and the second was positive for GFP (54.7\%). These results suggested that although our vector was "leaky", and since Rag2 ${ }^{-1-}$ mice do not have any CD19 cells in their lymph nodes, the UV-transformed B cells metastasized to the lymph nodes after 11 days post implantation. The metastatic cells not only persisted in the lymph nodes at day 18 (data not shown), but were also found metastasized to the spleen (Figure 4 E \& 4F). The metastatic cells were still detected in the spleen and lymph nodes at 27 days post implantation, and during this period these cells were also detected in the bone marrow (Figure 4H \& 4I). To determine whether the metastatic cells had migrated to other organs, we analyzed cell suspensions from the thymus, lung, liver and kidney, and found no evidence of these cells in any of these organs. These results indicate that the UV-induced B cell tumor cells were capable to metastasize to the bone marrow, spleen and lymph nodes, but not to any other tissue. 


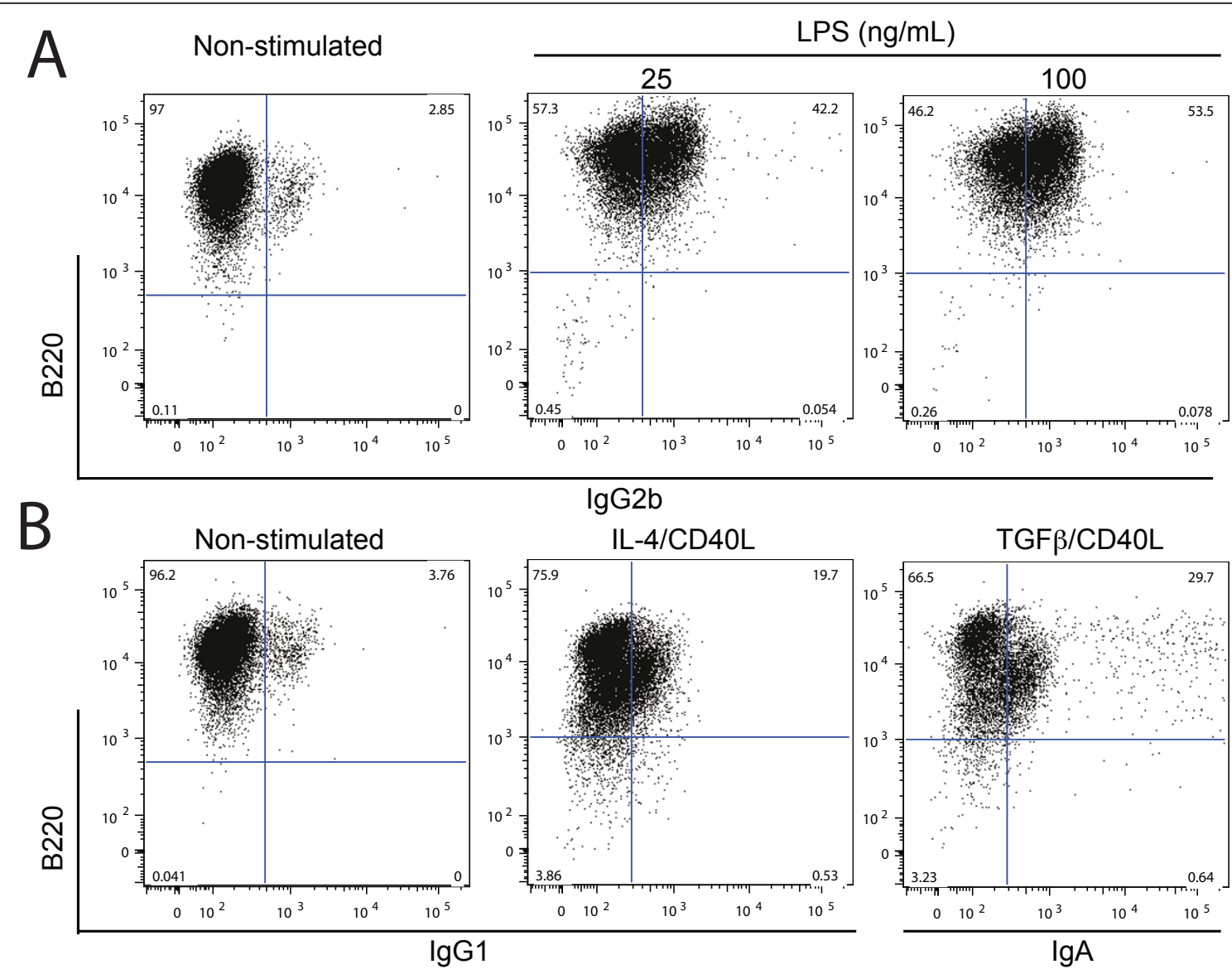

Figure 3 UVBL-1 cells exhibit a robust CSR in response to LPS stimulation. A. Flow cytometry analysis of untreated, 25 and $100 \mathrm{ng} / \mathrm{ml}$ LPS treated UVBL-1 cells undergo class switch recombination to lgG2b; B. Untreated, IL-4 ${ }^{+} \mathrm{CD} 40 \mathrm{~L}$ and $\mathrm{CD} 40 \mathrm{~L}^{+} \mathrm{TGF} \beta$ treated UVBL-1 cells class switch to $\lg G 1$ and $\lg A$ respectively.

The UV-induced tumor B cells are rich in IL-10 secretion To establish cytokine profiles, supernatant from cultured UV-induced tumor B cells were collected at various time points after the initiation of culture (24 to 72 hours). The production of a variety of cytokines by the cultured cells was analyzed using the Luminex system. Our results showed that the un-stimulated tumor cells only secreted IL-10 when cultured for 24 and $72 \mathrm{~h}$ in complete RPMI medium (Figure 5). These results indicate that IL-10 producing cells may have an increased advantage to promote their metastasis to other organs as observed in our analyses.

\section{Discussion}

We characterized the lymphoid tumors that arise in UVirradiated $\mathrm{p} 53^{+/-}$mice. No evidence of $\mathrm{T}$ cell tumors was found in this study. This may reflect the different way in which this study and our previous work was carried out. Our observation that UV exposure induced T cell tumors was based on a retrospective study in which histopathological analyses of paraffin-embedded tissue was used to determine the phenotype of the tumor [19]. Here, we generated tumors by injecting spleen cells isolated from UV-irradiated p53 heterozygous mice into Rag2-/- mice. The tumor cells were subjected to several passages in vivo until we were able to generate stable tumor cell lines that could grow in $\operatorname{Rag} 2^{-/-}$mice and in culture. From

Table 1 Growth of UV-induced B cell tumors in immune-deficient but not wild type mice

\begin{tabular}{cccc}
\hline Recipient Mice* & $\begin{array}{c}\text { Number of } \\
\text { mice }\end{array}$ & $\begin{array}{c}\text { Number with } \\
\text { tumor }\end{array}$ & p \\
\hline Rag2 & 15 & 15 & - \\
C57Bl/6 & 15 & 1 & 0.0001 \\
UV-irradiated C57Bl/6t & 15 & 2 & 0.0001 \\
\hline
\end{tabular}

* $2 \times 10^{6}$ tumor cells were injected into the subcutaneous space of the recipient mice. Tumor growth was monitored daily. Mice were sacrificed when the tumor volume exceeded $1 \mathrm{~cm}^{2}$.

$+10 \mathrm{~kJ} / \mathrm{m}^{2}$ UVB radiation, $3 x$ per week for 12 weeks prior to tumor transplantation.

₹ $p$ values determined by Fisher's exact test comparing tumor growth in immune deficient Rag $2^{-/-}$vs. growth in wild type or UV-irradiated wild type mice. 

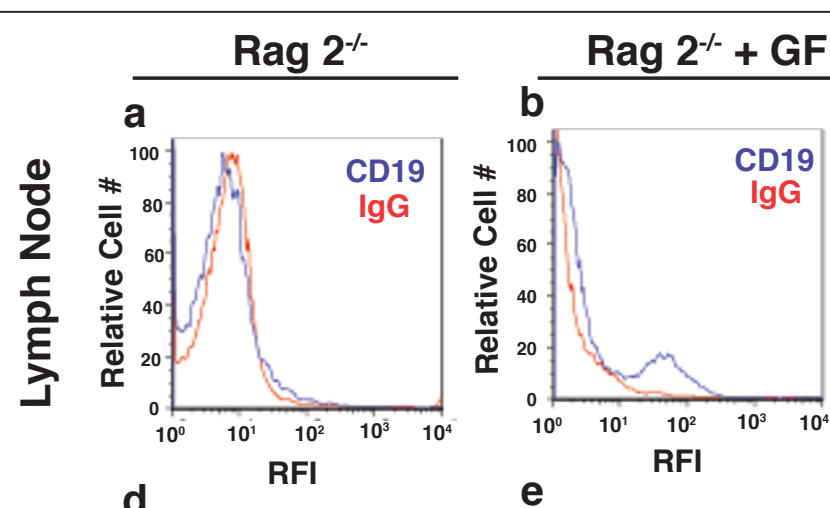

\section{CD19+UVBL-1}
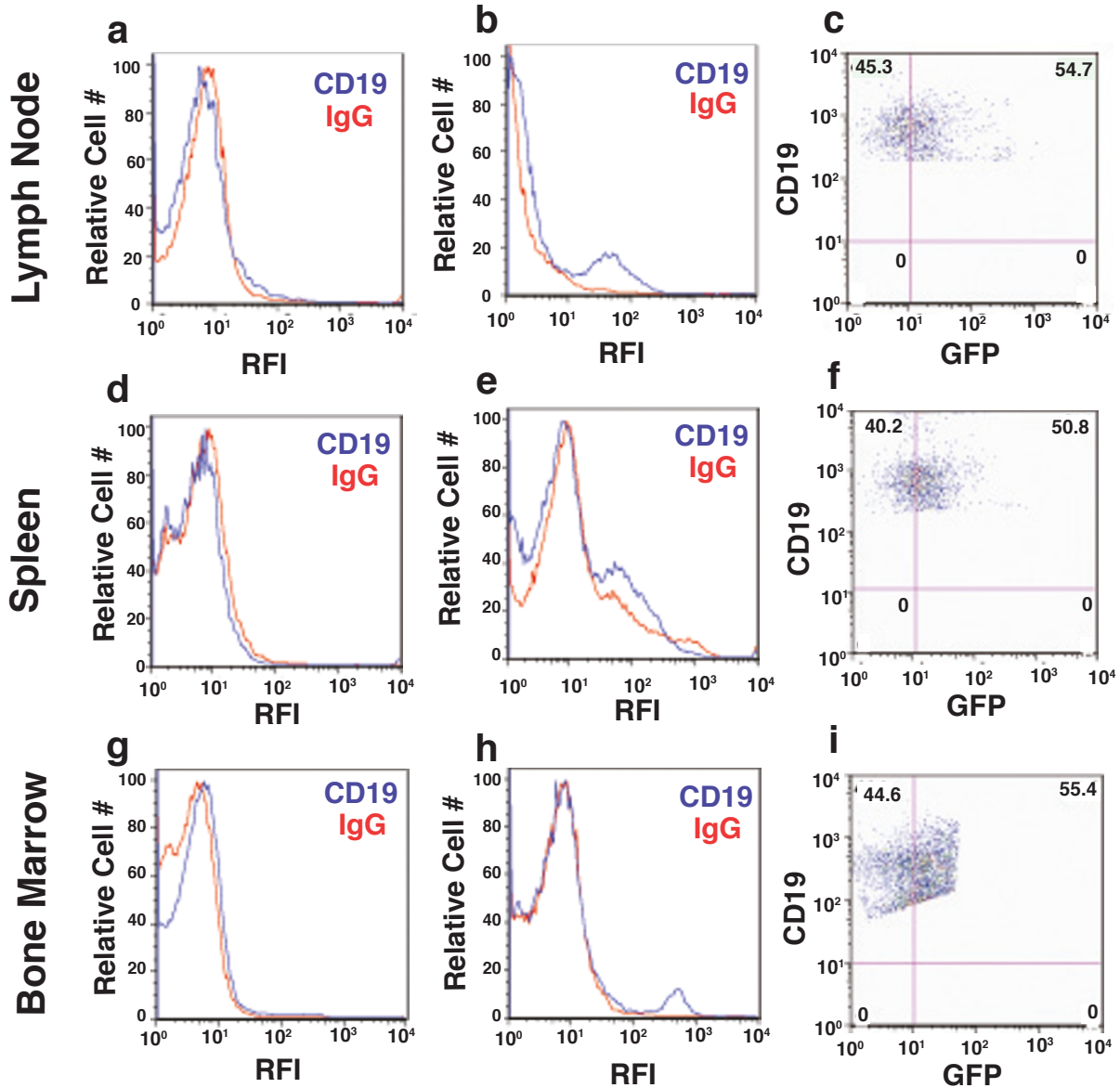

Figure 4 Metastatic behavior of the CD19+ $\mathbf{B}$ cell lymphoma. CD19+ UVBL-1 cells were transfected with GFP and injected subcutaneously into the flanks of Rag2 $2^{-1-}$ mice. Metastasis was analyzed 11, 18 and 27 days post injection. A: Background staining in the lymph nodes of Rag2 ${ }^{-1}$ mice; isotype staining in red; CD19 staining in blue. B: CD19 staining in the lymph nodes of Rag2 ${ }^{-1-}$ mice injected with UVBL-1; isotype staining in red; CD19 staining in blue. C: Double staining showing expression of CD19 by GFP positive cells Lymph node metastasis was analyzed 11 days post implantation. D: Background staining in the spleens of Rag2 $2^{-1}$ mice. E: CD19 staining in the spleens of Rag2 ${ }^{-1}$ mice injected with UVBL-1. F: Double staining showing expression of CD19 by GFP positive cells. Bone marrow metastasis was analyzed 27 days post injection. G: Background staining in bone marrow of Rag2 $2^{-1-}$ mice. $\mathrm{H}$ : CD19 staining in the spleen of mice injected with UVBL-1. I. Double staining showing expression of CD19 by GFP positive cells. Bone marrow metastasis was analyzed 27 days post injection. All other tissues examined (thymus, lung, live kidney) were negative.

these experiments we obtained three cell lines that grew in vivo but only one was also able to grow in vitro. It is possible that our "culture" favored the growth of B cells but not $\mathrm{T}$ cells. In one series of experiments, we phenotyped each successive in vivo passage, and in one of the earlier passages, we noted the presence of some $\mathrm{T}$ cell receptor positive cells (which by definition must be of tumor origin since the Rag2 ${ }^{-1-}$ mice cannot rearrange the $\mathrm{T}$ cell receptor). These cells were purified by cell sorting and then injected into Rag2 ${ }^{-1-}$ mice. No T cell tumors developed. This suggests that abnormal cells may have been present, but were not capable of growing progressively upon further passage in vivo.
It is interesting to compare our results to those previously published by MacPherson and colleagues [28]. In their study, transgenic mice were constructed with a point mutation in the murine p53 gene (serine 23 was replaced with alanine). These mice, which displayed defective apoptosis, had a reduced life span and most developed tumors. However, unlike the tumor spectrum found in $\mathrm{p} 53^{-1-}$ mice (predominately thymic lymphomas and sarcomas), the most common tumors found in homozygous p53 Ser23 mice were of B cell origin. The authors suggest that the long latency period to tumorigenesis in the p53 Ser23 mice provides the time required to acquire additional genetic changes to 


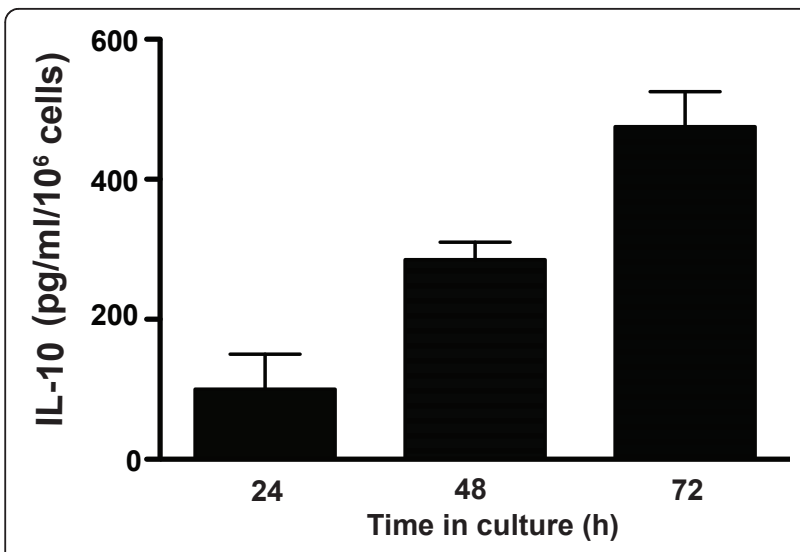

Figure 5 IL-10 secretion by the UV-induced B cell lymphomas The cells were grown in vitro without any further stimulation. Supernatants from duplicates of three Petri dishes were collected at 24, 48 and 72 hours and were analyzed individually. Each column represents the average in IL-10 concentration of 6 samples. The only cytokine detected in the supernatant fluid was IL-10. The bar indicates the standard error of the mean (SEM).

develop B cell tumors. We also note a long latency period for tumor development in our system, and as mentioned below, we suggest UV-induced inflammation may play a significant role.

Chromosomal analysis revealed a $\mathrm{t}(14: 19)$ translocation, which may play a role in UV-induced lymphomagenesis. However, to the best of our knowledge, a similar translocation has not been reported in lymphoma in the mouse. We analyzed the translocated region of chromosome 19 and found that this region contains the apoptotic genes Caspase 7 and programmed cell death 4, and the DNA cross-link repair 1a gene (SNM1a) which is involved in G1 cell cycle checkpoint downstream of ATM [29]. We suspect the $t(14 ; 19)$ translocation contributes to the deregulation of these and other genes and probably plays an important role in the oncogenic process in these cells. In addition, trisomy of chromosome 6 has been reported in chemically induced malignant skin tumors in TG.AC mice, which carry the v-Ha-ras transgene [30], and a similar imbalance has been reported in both benign and malignant skin tumors in the mouse [31]. Therefore, it is likely that the trisomy of chromosome 6 observed in our model is the result of the chronic exposure to UVB and probably it is also a contributing factor to the transformation of the UV-induced tumor B cells. We are currently exploring the possible deregulated oncogenes/tumor suppressors in these tumor cell lines.

What are the signals involved in the maintenance and proliferation of these tumors? Simple loss of heterozygosity does not appear to be an adequate explanation because when the B cell lymphomas were sequenced, we found they retained a normal wild-type p53 allele (data not shown). We favor the view that the immune suppression and chronic inflammation induced by UV exposure are involved. As noted above, the B cell lymphomas are highly antigenic. From our previous study we know that $\mathrm{p} 53^{+/-}$ mice are immune competent and UV exposure will induce immune suppression in these mice [19], so it is reasonable to assume that the immune suppression induced by chronic UV exposure provides a window that will allow these antigenic cells to grow in the UV-irradiated $\mathrm{p} 53^{+/-}$ mice. While it has been argued that an inverse association of sun exposure with NHL risk is related to the protective effects of vitamin D synthesis by UV radiation [15,32-36]; we know that the induction of systemic immune suppression following UV exposure of the skin is associated with the release of immune modulatory factors and immune suppressive cytokines. These may have direct relevance to the results reported here. The first is IL-10. UV-irradiation of the skin induces keratinocytes to secrete IL-10 $[37,38]$ and IL-10 can be found in the serum of UV-irradiated mice [39]. Moreover, IL-10 promotes the growth and differentiation of human B cells [40] and has been shown to promote the growth of B cell lymphomas [41,42]. Serum IL-10 is also considered to be a negative prognostic indicator for the survival of patients with non-Hodgkin's lymphoma [43]. The second is platelet-activating factor (PAF). PAF is a phospholipid that plays a primary role in the induction of inflammation. As the name implies PAF activates a wide variety of cells, including platelets, monocytes, mast cells and polymorphonuclear leukocytes [44]. PAF is secreted by epidermal cells almost immediately following UV exposure [45] and serves as a transcriptional activator for a variety of genes including cyclooxygenase (COX)-2, IL-6 and IL-10 [46,47]. PAF also plays an essential role in UV-induced immune suppression. Blocking the binding of PAF to its receptor, with a series of selective PAF receptor antagonists, blocks UV-induced transcription of COX-2 and IL-10 and blocks UV-induced immune suppression [47]. Normal and leukemic B cells express the PAF receptor $[48,49]$ and PAF has been shown rescue B cells from apoptosis [50].

Our results suggest the following scenario: the loss of a single p53 allele predisposes the B cells for transformation. Long-term chronic UV exposure then induces the release of inflammatory mediators by irradiated keratinocytes that promote tumor development. For example, UV-irradiated keratinocytes secrete macrophage migration inhibitory factor (MIF) [51], which can inhibit p53 tumor suppressor activity [52], thus resulting in a functional "loss of heterozygosity" in the UV-irradiated $\mathrm{p} 53^{+/-}$mice. Other UV-induced mediators of inflammation, such as PAF, may also play important roles in the process. First, PAF induces chronic inflammation, which appears to be associated with the induction of nonHodgkin's lymphoma [53]. Second, PAF binds to receptors on B cells and protects them from apoptosis. PAF 
up-regulates the transcription of COX-2 and IL-10. This is important because the expression of either prostaglandin $E_{2}$ or IL-10 has been associated with a poor prognosis in lymphoma patients [43,54]. In addition, both are immune suppressive, and we suggest UV-induced immune suppression (mediated by PAF, prostaglandin and IL-10), protects the developing antigenic B cell lymphoma from immune destruction. Our data provide a link between chronic UV exposure and the incidence of internal tumors in the 53 heterozygous background. Although there is no development of skin tumors in p53 heterozygous mice, somehow chronic UV exposure develops cellular transformation away form the site of exposure by a mechanism still under investigation.

\section{Conclusion}

We characterized the lymphoid tumors that arise in UVirradiated $\mathrm{p} 53^{+/-}$mice. The tumors were $\mathrm{CD} 5^{+}, \mathrm{CD} 19^{+} \mathrm{B}$ cell lymphomas that showed robust CSR capacity upon stimulation. The lymphomas secreted Il-10, which might help in the promotion of metastasis and lymphoma growth. Chromosomal analysis revealed a $\mathrm{t}(14 ; 19)$ translocation and trisomy of chromosome 6. Sequencing analysis indicated that the remaining p53 allele was intact, suggesting that an indirect mechanisms is involved in the generation of these tumors. In the future, we intend to try several therapies to block the induction of the UV-induced B cell lymphomas in $\mathrm{p} 53^{+/-}$mice including PAF receptor antagonist PCA-4248 treatment [55] or anti-IL-10 antibody therapy [56]. If successful, it may provide support for the hypothesis that the association between sunlight exposure and the development of nonHodgkin's lymphoma in humans is associated with chronic inflammation and the modulation of immune function by chronic UV exposure.

\section{Acknowledgements}

This work is supported by grants CA112660 and CA131207 (SEU) and CA116933 (CZ) from the National Cancer Institute, and the Leukemia Research Foundation, the American Cancer Society-Bonnie Kies Lymphatic System Research Scholar grant (C. Z.). The Animal, Cytogenetics and Histopathology Facilities at the MD Anderson Cancer Center are supported in part by a Cancer Center Support Grant (CA16672) from the National Cancer Institute.

\section{Author details}

'Department of Immunology and the Center for Cancer Immunology Research, The University of Texas M.D. Anderson Cancer Center, Houston, Texas, 77030, USA. ${ }^{2}$ The Graduate School of Biomedical Sciences, Houston, Texas, 77030, USA. ${ }^{3}$ Department of Hematology, Kyoto City Hospital, 1-2 higashitakada-cho, mibu, Nakagyo-ku, Kyoto, Japan 604-8845. ${ }^{4}$ Escuela Nacional de Ciencias Biológicas-IPN, Prol Carpio y Plan de Ayala S/N, Mexico D.F., Mexico.

\section{Authors' contributions}

NP: designed and performed experiments, interpreted results, drafted and revised the manuscript; YM, CS, AYL performed experiments, interpreted results, drafted the manuscript; NK performed experiments using animals;
SEU and CZ designed and supervised the research, analyzed the data and wrote and modified manuscript.

All authors read and approved the final manuscript.

\section{Competing interests}

The authors declare that they have no competing interests.

Received: 6 August 2010 Accepted: 26 January 2011

Published: 26 January 2011

\section{References}

1. Fisher SG, Fisher RI: The epidemiology of non-Hodgkin's lymphoma. Oncogene 2004, 23(38):6524-6534

2. Cartwright $R$, McNally $R$, Staines $A$ : The increasing incidence of NonHodgkin's lymphoma (NHL): the possible role of sunlight. Leukemia and Lymphoma 1994, 14:387-394.

3. Adami J, Gridley G, Nyren O, Dosemeci M, Linet M, Glimelius B, Ekbom A, Zahm SH: Sunlight and non-Hodgkin's lymphoma: A population-based cohort study in Sweden. Int J Cancer 1999, 80(5):641-645.

4. Brennan $P$, Coates M, Armstrong B, Colin D, Boffetta P: Second primary neoplasms following non-Hodgkin's lymphoma in New South Wales, Australia. Brit J Cancer 2000, 82:1344-1347.

5. Hu S, Federman DG, Ma F, Kirsner RS: Skin cancer and non-Hodgkin's lymphoma: examining the link. Dermatol Surg 2005, 31(1):76-82.

6. McMichael AJ, Giles GG: Have increases in solar ultraviolet exposure contributed to the rise in incidence of non-Hodgkin's lymphoma? Br J Cancer 1996, 73(7):945-950.

7. Bentham G: Association between incidence of non-Hodgkin's lymphoma and solar ultraviolet radiation in England and Wales. Brit Med J 1996, 312(7039):1128-1131

8. Freedman DM, Zahm SH, Dosemeci M: Residential and occupational exposure to sunlight and mortality from non-Hodgkin's lymphoma: composite (threefold) case-control study. Brit Med J 1997, 314(7092):1451-1455.

9. Hu S, Ma F, Collado-Mesa F, Kirsner RS: Ultraviolet radiation and incidence of non-Hodgkin's lymphoma among Hispanics in the United States. Cancer Epidemiol Biomarkers Prev 2004, 13(1):59-64.

10. Smedby KE, Hjalgrim H, Melbye M, Torrang A, Rostgaard K, Munksgaard L, Adami J, Hansen M, Porwit-MacDonald A, Jensen BA, et al: Ultraviolet radiation exposure and risk of malignant lymphomas. J Natl Cancer Inst 2005, 97(3):199-209.

11. Kricker A, Armstrong BK, Hughes AM, Goumas C, Smedby KE, Zheng T, Spinelli JJ, De Sanjose S, Hartge P, Melbye M, et al: Personal sun exposure and risk of non Hodgkin lymphoma: a pooled analysis from the Interlymph Consortium. Int J Cancer 2008, 122(1):144-154.

12. Grant WB: An estimate of premature cancer mortality in the U.S. due to inadequate doses of solar ultraviolet-B radiation. Cancer 2002, 94(6):1867-1875

13. Boscoe FP, Schymura MJ: Solar ultraviolet-B exposure and cancer incidence and mortality in the United States, 1993-2002. BMC Cancer 2006, 6:264

14. Grant WB, Garland CF: The association of solar ultraviolet B (UVB) with reducing risk of cancer: multifactorial ecologic analysis of geographic variation in age-adjusted cancer mortality rates. Anticancer Res 2006 26(4A):2687-2699.

15. Negri E: Sun exposure, vitamin D, and risk of Hodgkin and non-Hodgkin lymphoma. Nutr Cancer 62(7):878-882.

16. Adami J, Frisch M, Yuen J, Glimelius B, Melbye M: Evidence of an association between non-Hodgkin's lymphoma and skin cancer. Brit Med J 1995, 310(6993):1491-1495.

17. Levi F, Randimbison L, Te VC, La Vecchia C: Non-Hodgkin's lymphomas, chronic lymphocytic leukaemias and skin cancers. Br J Cancer 1996, 74(11):1847-1850.

18. Eaton GJ, Custer RP, Crane AR: Effects of ultraviolet light on nude mice: cutaneous carcinogenesis and possible leukemogenesis. Cancer 1978, 42(1):182-188.

19. Jiang W, Ananthaswamy HN, Muller HK, Ouhtit A, Bolshakov S, Ullrich SE, ElNaggar AK, Kripke ML: UV irradiation augments lymphoid malignancies in mice with one functional copy of wild-type p53. Proc Natl Acad Sci USA 2001, 98(17):9790-9795. 
20. Ullrich SE: Mechanisms underlying UV-induced immune suppression. Mutat Res 2005, 571(1-2):185-205.

21. Setlow RB, Grist E, Thompson K, Woodhead AD: Wavelengths effective in induction of malignant melanoma. Proc Natl Acad Sci USA 1993, 90:6666-6670

22. Nghiem DX, Kazimi N, Clydesdale G, Ananthaswamy HN, Kripke ML, Ullrich SE: Ultraviolet a radiation suppresses an established immune response: implications for sunscreen design. J Invest Dermatol 2001, 117(5):1193-1199.

23. Manis JP, Morales JC, Xia Z, Kutok JL, Alt FW, Carpenter PB: 53 BP1 links DNA damage-response pathways to immunoglobulin heavy chain classswitch recombination. Nat Immunol 2004, 5(5):481-7.

24. Edry E, Koralov SB, Rajewsky K, Melamed D: Spontaneous class switch recombination in $B$ cell lymphopoiesis generates aberrant switch junctions and is increased after VDJ rearrangement. J Immunol 2007, 179(10):6555-6560.

25. Kripke ML: Antigenicity of murine skin tumors induced by ultraviolet light. J Natl Cancer Inst 1974, 53(5):1333-1336

26. Fisher MS, Kripke ML: Suppressor T lymphocytes control the development of primary skin cancers in ultraviolet-irradiated mice. Science 1982, 216(4550):1133-1134.

27. Moodycliffe AM, Nghiem D, Clydesdale G, Ullrich SE: Immune suppression and skin cancer development: regulation by NKT cells. Nat Immunol 2000, 1(6):521-525.

28. MacPherson D, Kim J, Kim T, Rhee BK, Van Oostrom CT, DiTullio RA, Venere $\mathrm{M}$, Halazonetis TD, Bronson R, De Vries A, et al: Defective apoptosis and B-cell lymphomas in mice with p53 point mutation at Ser 23. Embo J 2004, 23(18):3689-3699.

29. Akhter S, Legerski RJ: SNM1A acts downstream of ATM to promote the G1 cell cycle checkpoint. Biochem Biophys Res Commun 2008, 377(1):236-241.

30. French JE, Libbus BL, Hansen L, Spalding J, Tice RR, Mahler J, Tennant RW: Cytogenetic analysis of malignant skin tumors induced in chemically treated TG-AC transgenic mice. Mol Carcinog 1994, 11(4):215-226

31. Kemp CJ, Fee F, Balmain A: Allelotype analysis of mouse skin tumors using polymorphic microsatellites: sequential genetic alterations on chromosomes 6, 7, and 11. Cancer Res 1993, 53(24):6022-6027.

32. Garland CF, Gorham ED, Mohr SB, Garland FC: Vitamin D for cancer prevention: global perspective. Ann Epidemiol 2009, 19(7):468-483.

33. Garland CF, Garland FC, Gorham ED, Lipkin M, Newmark H, Mohr SB, Holick MF: The role of vitamin D in cancer prevention. Am J Public Health 2006, 96(2):252-261.

34. Ingraham BA, Bragdon B, Nohe A: Molecular basis of the potential of vitamin D to prevent cancer. Curr Med Res Opin 2008, 24(1):139-149.

35. Krishnan AV, Trump DL, Johnson CS, Feldman D: The role of vitamin D in cancer prevention and treatment. Endocrinol Metab Clin North Am 39(2):401-418, table of contents.

36. Drake MT, Maurer MJ, Link BK, Habermann TM, Ansell SM, Micallef IN, Kelly JL, Macon WR, Nowakowski GS, Inwards DJ, et al: Vitamin D insufficiency and prognosis in non-Hodgkin's lymphoma. J Clin Oncol 28(27):4191-4198.

37. Enk CD, Sredni D, Blauvelt A, Katz SI: Induction of IL-10 gene expression in human keratinocytes by UVB exposure in vivo and in vitro. I Immunol 1995, 154:4851-4856.

38. Rivas JM, Ullrich SE: Systemic suppression of delayed-type hypersensitivity by supernatants from UV-irradiated keratinocytes. An essential role for keratinocyte-derived IL-10. J Immunol 1992, 149(12):3865-3871.

39. Rivas JM, Ullrich SE: The role of IL-4, IL-10, and TNF-alpha in the immune suppression induced by ultraviolet radiation. J Leukoc Biol 1994, 56(6):769-775.

40. Rousset F, Garcia E, Defrance T, Peronne C, Vezzio N, Hsu DH, Kastelein R, Moore KW, Banchereau J: Interleukin-10 is a potent growth and differentiation factor for activated human B lymphocytes. Proc Natl Acad Sci USA 1992, 89:1890-1893.

41. Masood R, Zhang Y, Bond MW, Scadden DT, Moudgil T, Law RE, Kaplan MH, Jung B, Espina BM, Lunardi-lskandar Y, et al: Interleukin-10 is an autocrine growth factor for acquired immunodeficiency syndrome-related B-cell lymphoma. Blood 1995, 85(12):3423-3430.

42. Voorzanger N, Touitou R, Garcia E, Delecluse HJ, Rousset F, Joab I, Favrot MC, Blay JY: Interleukin (IL)-10 and IL- 6 are produced in vivo by
non-Hodgkin's lymphoma cells and act as cooperative growth factors. Cancer Res 1996, 56(23):5499-5505.

43. Blay JY, Burdin N, Rousset F, Lenoir G, Biron P, Philip T, Banchereau J, Favrot MC: Serum IL-10 in Non-Hodgkin's Lymphoma: A prognostic factor. Blood 1993, 82(7):2169-2174.

44. Zimmerman GA, McIntyre TM, Prescott SM, Stafforini DM: The plateletactivating factor signaling system and its regulators in syndromes of inflammation and thrombosis. Crit Care Med 2002, 30(5 Suppl):S294-301.

45. Barber LA, Spandau DF, Rathman SC, Murphy RC, Johnson CA, Kelley SW, Hurwitz SA, Travers JB: Expression of the platelet-activating factor receptor results in enhanced ultraviolet $B$ radiation-induced apoptosis in a human epidermal cell line. J Biol Chem 1998, 273(30):18891-18897.

46. Pei Y, Barber LA, Murphy RC, Johnson CA, Kelley SW, Dy LC, Fertel RH, Nguyen TM, Williams DA, Travers JB: Activation of the epidermal plateletactivating factor receptor results in cytokine and cyclooxygenase-2 biosynthesis. J Immunol 1998, 161(4):1954-1961.

47. Walterscheid JP, Ullrich SE, Nghiem DX: Platelet-activating factor, a molecular sensor for cellular damage, activates systemic immune suppression. J Exp Med 2002, 195(2):171-179.

48. Nguer CM, Treton D, Rola-Pleszczynski M, Mishal Z, Thomas Y, Galanaud P, Richard Y: Regulation of platelet-activating factor receptor expression in human B cells and B cell lines. Lipids 1996, 31(10):1051-1058.

49. Denizot $Y$, Donnard M, Guglielmi L, Faucher JL, Jaccard A, Bordessoule D, Trimoreau F: Detection of functional platelet-activating factor receptors on leukemic B cells of chronic lymphocytic leukemic patients. Leuk Lymphoma 2004, 45(3):515-518.

50. Toledano BJ, Bastien Y, Noya F, Mazer B: Characterization of B lymphocytes rescued from apoptosis by platelet-activating factor. Cell Immunol 1999, 191(1):60-68.

51. Shimizu T, Abe R, Ohkawara A, Nishihira J: Ultraviolet B radiation upregulates the production of macrophage migration inhibitory factor (MIF) in human epidermal keratinocytes. J Invest Dermatol 1999, 112(2):210-215.

52. Hudson JD, Shoaibi MA, Maestro R, Carnero A, Hannon GJ, Beach DH: A proinflammatory cytokine inhibits $p 53$ tumor suppressor activity. J Exp Med 1999, 190(10):1375-1382

53. Smedby KE, Hjalgrim H, Askling J, Chang ET, Gregersen H, PorwitMacDonald A, Sundstrom C, Akerman M, Melbye M, Glimelius B, et al: Autoimmune and chronic inflammatory disorders and risk of nonHodgkin lymphoma by subtype. J Natl Cancer Inst 2006, 98(1):51-60.

54. Hazar B, Ergin M, Seyrek E, Erdogan S, Tuncer I, Hakverdi S: Cyclooxygenase-2 (Cox-2) expression in lymphomas. Leuk Lymphoma 2004, 45(7):1395-1399.

55. Sreevidya CS, Khaskhely NM, Fukunaga A, Khaskina P, Ullrich SE: Inhibition of photocarcinogenesis by platelet-activating factor or serotonin receptor antagonists. Cancer Res 2008, 68(10):3978-3984.

56. Rivas JM, Ullrich SE: The role of IL-4, IL-10, and TNF-alpha in the immune suppression induced by ultraviolet radiation. J Leukoc Biol 1994, 56(6):769-775

Pre-publication history

The pre-publication history for this paper can be accessed here: http://www.biomedcentral.com/1471-2407/11/36/prepub

\section{doi:10.1186/1471-2407-11-36}

Cite this article as: Puebla-Osorio et al.: Induction of B-cell lymphoma by UVB Radiation in p53 Haploinsufficient Mice. BMC Cancer 2011 11:36. 